\title{
GIS AND 3D MODELS AS SUPPORT TO DOCUMENTATION AND PLANNING OF THE BAKU HISTORICAL CENTRE (REPUBLIC OF AZERBAIJAN)
}

\author{
Laura Baratin ${ }^{\mathrm{a}}$, Sara Bertozzi ${ }^{\mathrm{a}}$, Elvio Moretti ${ }^{\mathrm{a}}$, Michele Spinella ${ }^{\mathrm{b}}$, \\ ${ }^{a}$ DiSBEF - University of Urbino, Campus Scientifico „E. Mattei“, 60129 Urbino, Italy \\ \{laura.baratin,sara.bertozzi,elvio.moretti\}@uniurb.it \\ ${ }^{\mathrm{b}}$ GESP s.r.1. Italy, spinella@gesp.it
}

KEY WORDS: GIS, 3D MODEL, CONSERVATION, HISTORIC CITY, SPATIAL ANALYSIS, GEOREFERENCING

\begin{abstract}
:
The walled city of Baku, Icherisheher has been described as one of the best examples of a city that has retained its historical stratigraphy in over a thousand years, where the different influences and its evolution in time may be appreciated. In realising the Master Plan of the historical city, many problems were solved with different information technologies (GIS, DEM, DTM, etc.) for the survey and data mapping management during all the phases of the project. Initially the analysis was addressed to systematic reading of the documents collected during the iconographic study, verifying the process of deterioration that the historic city had suffered during various periods from the Khans to the Tsarist domain, and from the Republic of Azerbaijan to the Soviet period through to its independence. The entire central part of the historic city was analyzed, including not only on its special architectural and urban monuments, but even minor buildings, which are in part still intact, used as a basis for a digital map created in order to focus on Baku's historical evolution. A three-dimensional model of the historic centre of Baku was then produced as a basis not only for virtual navigation in real time, but as additional support for planning studies and to better understand the principles of various design choices. The request to produce a model in VRML format addressed the choice of better modelling methods. The combination of these different technologies and their application in the analysis of historical cities led to further considerations on data acquisition systems, standardization of formats, the use of survey instruments and the use of different software, etc., all fundamental elements to the define their correct use.
\end{abstract}

\section{INTRODUCTION}

The ancient city was stratified in time with morphological and structural parameters that originated from cultures that progressed in a correlated manner with the development of urban economy, that was initially mercantile, later commercial and finally industrial. With the advent of capitalism and the birth of the extractive and industrial economy, these relationships changed and the pace, which was asynchronous with respect to the adaptation potential of the urban structure, had an enormous impact on the historical stratification of the city, producing functional modifications that changed the city from a unitary whole to a structure used only in parts. Recovery of the ancient city, intended not as a fait accompli incompatible with its current functional needs, but an important element of the democratic use of its cultural, social and economic heritage, must necessarily be based on research work and analysis of these stratification, expansion and alteration processes, considered however from a new perspective, namely no longer interpreted empirically simply from an historical point of view and isolated from the factors that induced the same, but seen in a broader social, political and economic sense and above all in their original symbolisation, without filtering the same through the Russian literature of the nineteenth century and beyond, which is something that today is still intentionally done. While recognising today that the historical centre of di Baku is the ultimate result of a unitary process of historically complete formation, it is however possible to clearly re-interpret the single "stratifications" of this process of formation. When Baku, which was founded as a mercantile trading post at a port along the silk road, became a commercial city it underwent a first planned transformation when it was chosen ( $\mathrm{XV}^{\text {th }}$ century) as the capital of the kingdom of Shirvanshah and was characterised by a strong interpenetration of different social classes. Over the years the city played a double role: as commercial centre in the upper part of the city around the fortress of Shirvanshah, and as trading post in the lower part of the city, next to the Silk Road between the Southern and Northern parts of the city, facing the port where the third city gate was located. The two sections of the city coexisted but there was no interpenetration, so that while the upper town was above all used for residential purposes, the lower town city was characterised by bazaars, caravan ins, the central mosque, workshops and storerooms. The city walls were completed in the $\mathrm{XV}^{\text {th }}$ century but outside the walls there were villages which were contemporaneous if not prior to the city itself that for years housed the fortified residences of different governors. Thanks to its commercial and market activities, the city became a flourishing cosmopolitan city and a point of reference for the entire Transcaucasian area, even along the sea routes of the Persian and Russian empires. It was for this very reason that it was disputed by these two great powers, until towards the middle of the XVIII ${ }^{\text {th }}$ century and the early XIX $^{\text {th }}$ century, it was finally occupied by the Russian empire. Between the $X^{\text {th }}$ and the XVIII ${ }^{\text {th }}$ centuries the most important changes were to the defence lines, to which a second fortified boundary wall and bastions were gradually added. With the advent of the Russians, the city which up to then had adapted synchronously to different cultures and had a uniform urban fabric with its own architectural features, underwent a traumatic transformation. From a gradual process of stratification of styles and features, the city underwent a drastic "superimposition" of typically Russian buildings. From a cosmopolitan socially interpenetrated centre, the city became a centre of occupation. After building infrastructures of authority and power such as army barracks, administration headquarters, prisons and so on, the Russians gradually proceeded to demolish the signs of the past. Many mosques were deconsecrated and the homes of the more prominent families 
destroyed. The identity of the city itself was denied. After building a new city on the exterior, presumably where the fortress of the last Khan stood, the Russians proceeded to disintegrate the historical urban fabric by demolishing many defence features (walls and bastions). Even the dock facing the historical city was replaced by a linear port that extended along the coast. On this new clearing a curtain of new commercial buildings was raised to hide the city itself. In 2002 the city was listed as a UNESCO World Heritage site to support conservation and protection processes, above all because degradation and destruction of monuments and buildings of the traditional and historical fabric had significantly compromised its architectural integrity, in particular after the earthquake in 2000. Only from 2000 to 2009, after the UNESCO listing, was it considered to be important to create a general plan containing guidelines that would uniform the urban fabric in the territory, by incorporating past provisions and introducing new rules in order to create an efficient reference law.

The creation of an efficient Master Plan also meant the introduction of a very important monitoring phase. This made it possible to document the changes that had occurred and effectively compare current conditions and future objectives. The monitoring phase includes regular controls but only once responsibilities and method of collaboration between the various authorities have been defined.

\section{THE BAKU GIS: A NUMBER OF PROBLEMS}

Research work and analyses focused on the phenomena of genesis which are still present today, attempting above all to localise the processes which with the advent of Russian domination altered these phenomena, and produced the current physiognomy and use of the Historical Centre. A methodological interpretation of the genesis, based on reliable visual records, firstly summarises a systematic analysis of the formation of the city, focusing on the generating elements, and then verifies the process of alteration that the city within the walls underwent in two hundred years of Tzarist domain and seventy years as a Soviet Republic. This analysis of the Historical Centre, intended not only as monuments of particular architectural and urban importance but also the lesser urban fabric, which is substantially still intact, is the basis of the digital map produced to represent its historic evolution.

\subsection{Georeferencing}

The particularity of a GIS project is that in order to represent and manage the spatial information of a specific territory, it uses a representation of spatial data separated from the physical reality but defined by a specific spatial reference system on which the data are entered. The geographic dislocation of each part of the computer system is indicated by a specific Reference Geodetic System which makes it possible to georeference the project.

When working in field like that of cultural heritage and dealing with international projects and problems, it is essential to use a georeferencing system which is recognised and applied at a global level to plan the project. The only geodetic system which meets this requirement and is applicable on a global scale is the WGS84 (World Geodetic System 1984, world geodetic system referring to 1984). Traditional geodetic systems are in fact generally based on ellipsoids positioned in space, using the astrogeodetic method, tangent to the local geode in a central point of the area in question; the ellipsoid associated to the WGS84 not only has a different shape and dimensions but its geometric centre coincides with the barycentre of the Earth and with no relation to its surface. It is a mathematical model of the Earth from a geometric, geodetic and gravitational point of view, but because it is based on a system of geographic coordinates, it has two fundamental disadvantages: the use of decimal degrees as unit of measure that do not permit aerial processing of the various items and polygon distortions which depend on the land surface of the area in question, and which increase proportionally the further you move away from the equator. These problems are resolved however thanks to the fact that the WGS84 associates perfectly to UTM plan projection (Universal Transverse Mercator). This system subdivides the terrestrial surface into 60 time zones having $6^{\circ}$ longitude as from Greenwich, and in 20 bands having latitude of $8^{\circ}$. Intersection of the time zones and bands generates 1200 zones which in turn are subdivided into squares with $100 \mathrm{~km}$ sides, marked by two capital letters. The project can therefore be georeferenced by identifying the area in which the cultural heritage is located, using a metric system and preventing distortions. The system is also fully compatible with the WGS84, so that the shapefiles created in the various UTM systems may be all be imported into a single project in the WGS without transformations. Considering the above, the WGS 1984 UTM Zone 39N was chosen as the reference system for the GIS project for walled city of Baku. The first step was to import a "cleaned" map produced with CAD software into GIS environment, in order to have a database with which to start constructing the space in question. The entire historical centre was thus created, polygon by polygon, identified by the shapefile "Buildings", to which further layers such as "Externalbuildings", "Walls", "Green_areas", "Green_areas_centre", "Caspian_Sea" were added, and assigned to the respective shapefiles in order to complete the map square representative of the territory. Once the map construction of the area had been completed, a data platform was created for queries, by entering in the table the characteristics of the building number, the block number, the Mahalla number (local subdivision of the block), address and street number, ownership (whether public or private), use, type of building, periodization, state of conservation and planned restructuring works, in order to provide to planners a large number of data to identify the single building units and manage the urban functions of the territory. The building categories grouped by historical period, to which their genesis refers, were also taken into account. The aerial dimensions of all the buildings in each group were then calculated and associated to the entire extension of the building fabric of the historical centre.

\subsection{Spatial Analysis}

The Spatial Analysist tools of the ArcGIS make it possible to explore and analyse data according to their spatial position and weighted data in order to obtain a fuzzy logic (FL) based aerial view. In this context, the FL provides a simple way to reach conclusions on the basis of data which are at times not only vague and ambiguous but even inaccurate or altogether missing. Fuzzy Logic queries and changes the concept of binary logic according to which data may only be either true or false. When applied to the territory and environment, binary logic is imprecise and does not correspond to reality which includes many-faceted aspects that are not taken into account or rather approximated with this method of interpreting space.

In the real world and in this specific case, a number of particular characteristics were taken into account, such as the State of conservation, conservation works, aerial dimensions and historical period defined by points. Each of these aspects is defined in the characteristics table by various classification categories on the basis of which values in a scale from 0 to 1 were allocated, with growing importance to 1'1. Consequently the oldest areas, those characterised by better conservation and 
key buildings having an important function in the city are graded as 1 , scaling down to zero as importance decreases. These parameters may reciprocally impact each other according to proximity of the points and interactions between the various characteristics that may be evaluated using the extension Spatial Analyst di Arcgis of ESRI. This tool makes it possible to process interpolations thanks to which the intermediate values of a function may be estimated according to geographic proximity logics. Arcgis has various moving-average interpolators: IDW, Spline, Kriging and Natural Neighbour. These systems are used to calculate the values of areas when data are not available for the variable described with algorithms that calculate the average of points in proximity of each cell, inversely weighted with respect to the distance, also taking into account in some cases the autocorrelation of the points measured. In other words, the values of the grid cells do not only depend on the value of the known points but also on their spatial layout. In this way each point is not simply evaluated as a unit in itself but the interaction of the environment on the same may also be evaluated. Significant interpolation is obtained from the real representation of the influence that urban mosaics share. This was the reason to identify this complexity, which according to the data entered, reprocesses a new and different concept that does not simply reflect what has already been observed.

The comparison algorithm is based on the concept of Natural Neighbours and Voronoi polygons. The Voronoi diagram is a special decomposition of metric space determined by the distance to a specified family of objects (subsets) in the space (for example a finite set of points as in the case of the points described in this project).

In the simplest and most common case of the plane, given a finite set of points $S$, the Voronoi diagram for $S$ is the partitioning of the plane that associates a region $\mathrm{V}(\mathrm{p})$ to each point $P$ belonging to $S$ in such a way that all the points of $V(p)$ are closer to $\mathrm{p}$ than to any other point in $\mathrm{S}$.

The natural neighbours spatial interpolation method was developed by Robin Sibson [1] based on the Voronoi diagram of a discrete set of points distributed on the Euclidean space. This algorithm does not arbitrarily define the surface and also offers the following advantages: it respects experimental data without filtering the same and the resulting surface is regular (continuous and to the first derivative, derivable anywhere other than on the data observed), thus approximating the phenomenon interpreting as "faithfully" as possible.

The equation in a bi-dimensional space is the following:

$$
G(x, y)=\sum_{i=1}^{n} w_{i} f\left(x_{i}, y_{i}\right)
$$

Where

$\checkmark G(x, y)$ is the estimate to the position $(x, y)$

$\checkmark \quad w_{i}$ are the weights

$\checkmark f\left(x_{i}, y_{i}\right)$ are the known data for the pair of coordinates $\left(x_{i}, y_{i}\right)$

This method proposes a measure to calculate the weights and select the neighbours to interpolate. It also uses the Voronoi diagram to calculate the weight associated to each point.

Given the Voronoi diagram for a distribution of the points in space and given a regular interpolation grid consisting of a finite number of points that we will call $p_{i}$, the method considers the Voronoi diagram to calculate the weight $w_{i}$ of the node of grid $\mathrm{p}_{\mathrm{i}}$ as shown by the drawing

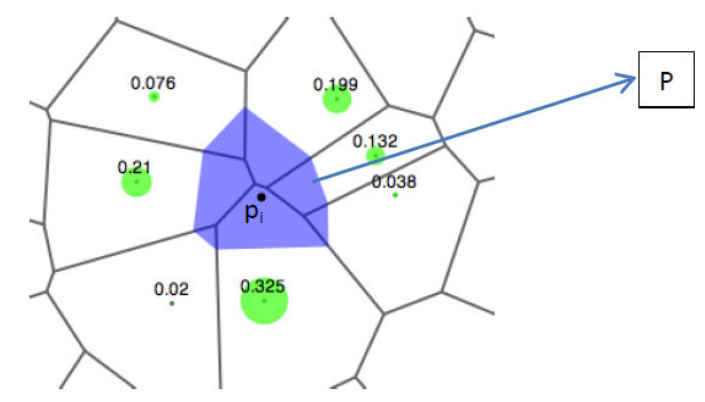

Figure : Interpolation of natural neighbours, calculation of the weight

The weight is calculated according to the area given by intersection of $\mathrm{P}$ with the existing polygons, so that a larger area corresponds to a higher weight. Thanks to the weighted subdivision of the space studied in adjacent areas, the Voronoi diagram makes it possible to study the spatial distribution and continuity of the phenomenon. Areas with a higher number of points and where the phenomenon is more uniform, may therefore be identified by appropriate teeming.

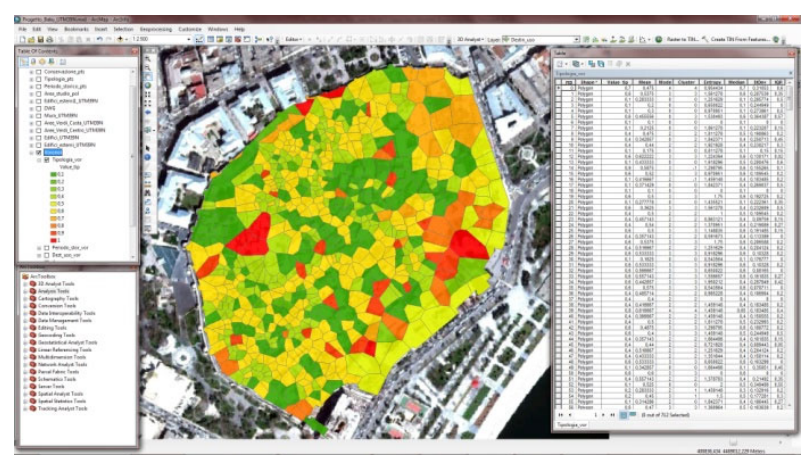

Figure 2: Processing of the area by Voronoi Diagram

Interpolation on the other hand "flattens" the data on a regular grid, representing the phenomenon in the form closest to real life. Natural neighbour interpolation may be used to highlight continuous structures in the space.

In this project, the Voronoi diagram was generated with the "Create Thiessen Polygons (Analysis)" function while natural neighbour interpolation was calculated with the function "Natural Neighbours" in the "Spatial Analyst" Toolbox.

The rasters obtained were displayed according to a signal scale with 3600 colour shades ranging from green (low values) to red (high values) through yellow (medium values), based on fuzzy logic. The different rasters were then overlaid using the Overlay tool in Spatial Analyst Tools, called "Fuzzy Overlay". The function "AND" was then used to join the rasters defined by "stretched" symbology to create a new single raster. 


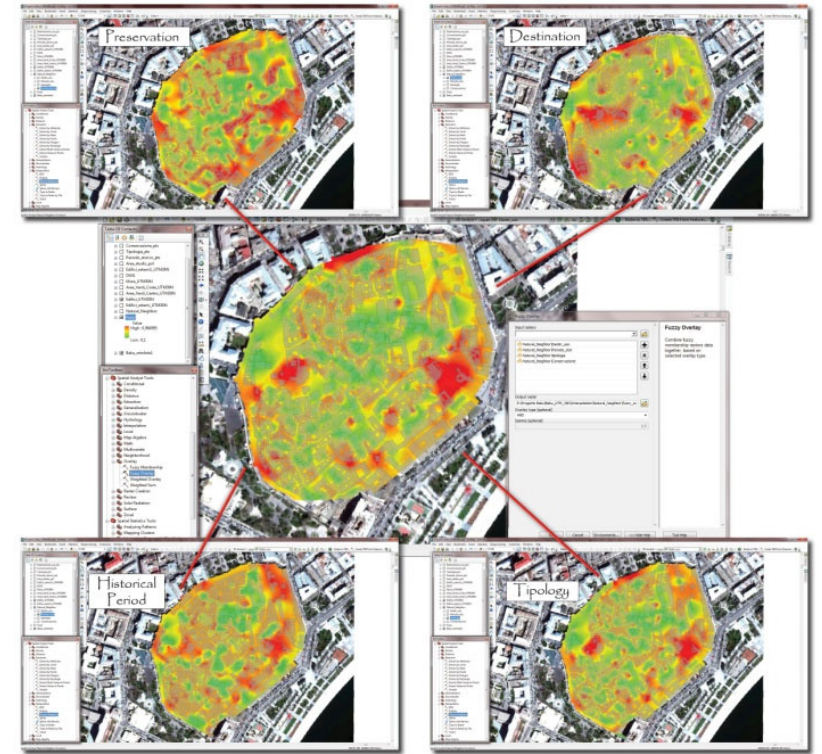

Figure 3: Different rasters obtained by "Natural Neighbour" interpolation which were then summed according to overlay logics between fuzzy rasters

This above shows that the most interesting section in terms of conservation is that in the North, East and South where connectivity is high so that minor interventions would easily improve the architectural value as a whole, while more significant interventions would be necessary in the central and western areas which are smaller and more detached from each other. This type of visualisation complies perfectly with FL since the territory is not visualised by discrete entities but as a continuous territorial fabric, gradually passing from a lower to a higher value. This undoubtedly innovative and on the whole analytic methodology quite obviously does have some limits, the most significant of which involves the edges of the interpolation area. In proximity of the outlines, there is an objective limit in terms of calculating the reciprocal influence between different points, in that the points on the outer edge of the area cannot interact with the territory beyond this and even if contiguous with the same, cannot in any way affect the final result. Interpolation in fact "invents" points on the edge. To remove these, a clip polygon must be created, which limits processing to the perimeter of the points provided: the operation was carried out by extracting the perimeter of the data available (grid complete with valid grid nodes) and clipping with ArcToolBox/Spatial Analyst/Extraction/Extract by Mask.

\section{MODEL OF THE HISTORICAL CITY}

A 3D model of the historical centre of Baku was then produced, not only to allow virtual navigation in real time but as additional support to planning in order to better understand the various project choices. The need to produce a model in VRML format addressed the choice of methodologies to use in modelling. Work was based on the urban structure of the city and a separation of individual areas into single objects with various levels of details; in addition to modelling activities, images to apply to the faces of the model were produced, through to completion. This format, which is a simple open text file (which is not coded and can therefore be modified with any text editor), permits entering the characteristics of the model polygons. Vertexes, edges, surface colours, textures, brightness and transparency etc. may be defined in the same. Regardless of the software tool used for modelling, the same would need to produce objects consisting of basic units, easily convertible to this format (WRL). Low-poly modelling was also clearly necessary, in other words using the lowest possible number of polygons, in view of the numerous objects to represent at the same time. Generally speaking, all the CAD programmes which operate in a $3 \mathrm{D}$ space, have these characteristics. The apparently obvious of using AUTOCAD (Autodesk) was made for three main reasons:

- the fact that it is commonly used;

- the fact that the file structure may be rigidly organised, by controlling the levels (layers), colours (no more than 256) and names of the latter (and thus using specifications common to all the models);

- the fact that the software can generate an interexchange format comprehensible to the software used to allocate the textures (maps) to the surfaces of the models. Version 10.1 of Cinema 4D (Maxon) was used for this. This packet was preferred over more popular packets such as the 3DS MAX (AutodeskKinetix), because of its tried and tested strong points: operational stability, extreme flexibility for the management of complex objects, good compatibility in terms of importing and exporting other formats.

Organisation of the basic material suggested right from the start the possible organisation for the management of $3 \mathrm{D}$ data. A "minimum" element identified in the fairly chaotic urban context, which developed within a wall hemicycle in fact included the so-called "Isolated" elements. Each of these is a unique element, enclosed in itself, that may therefore be treated as a separate element in the model as a whole. Joining all the isolated elements (approximately 99) within the city walls, would have represented the building volumes as a whole of the ancient part of the city. A structure of this kind made it possible to take into account, within each "Isolated" unit, the sub-units of which the isolated unit consists, namely the Elevations (total fronts on one side of the isolated element) and the facades of the single buildings, of which the Elevations are in turn composed. The documents showed that on average each isolated element consisted of 4-5 Elevations which in turn consisted of a variable number of individual buildings, corresponding to several hundred single buildings. Some isolated elements consisted of just one building, while others consisted of dozens of different buildings. Entering the isolated elements into a single C4D file, produced an object in which the reciprocal planimetric position of each isolated element was that of the original plan. There were some instances of interference and overlapping (but only of sections of isolated elements), that were resolved by selecting and moving the vertexes in question, with respective "deformation" of the original geometry. These modifications were on the whole not extremely visible, thanks to re-adaptation of mapping to the surfaces. There movements in any case occurred in small circumscribed areas and were resolved locally, without repercussions on the general structure of the isolated elements themselves. Overlapping was mainly due to the smallness of the spaces that separated the isolated elements. In very many cases, the total width of the alley was less than a metre. The "global" file had a hierarchy of a total of 96 isolated elements, ordered in sequence (isolated elements 1, 74, 75 are missing because they were demolished), plus one object representing the walls. Right from the start, the configuration of the ground inside the walls, was founded to be extremely complex. Continuous ups and downs, above all on the fronts, indicated a very uneven morphology, with many points of discontinuity, differences in level, steps, uphill and downhill slopes, which in many cases were very steep. This led to the idea of using the "profiles" in the facades to generate surfaces locally that, when summed, would give an acceptable basic closure. Because of the way the project was structured, it would not have been possible to model the ground until all the isolated elements and relevant mapping were completed. An alternative 
might have been to carry out modelling and mapping, by contrasting isolated elements, but this would in any case be difficult because of the way the work loads had been shared between the modellers, and the different times required to complete the different parts. Although the methods created to produce and control the built-up parts of the city were complex, they gave excellent results. The model of the isolated elements is, in fact, as far as possible and given the data available, scientifically correct and easy to use. Other than in a very few cases, which were in any case resolved fairly easily, there were no particular cases entailing survey or modelling errors, that precluded the closure or resolution of the single isolated-units. The altimetric aspects and resolution of the basic ground were a different matter. These aspects in fact caused the most critical problems. In the case of Baku, it will be shown that the new three-dimensional processing carried out in different 3D environments, may be an efficient representation of the urban fabric, which may generate new knowledge and studies in the field of urban sciences.

The new potential of digital representation of urban spaces is radically changing the way the city is studied and analysed. Many studies have attempted to explore the possibilities of 3D representation of the city, even in terms of defining new forms of analysis and interpretation, through the perceptive interaction this modelling permits. 3D models make it possible to represent the physical structure of the city, which may in turn be analysed, in order to define how a residential or cultural urban function characterises a specific context and relationships with other activities, thus representing an efficient possibility of investigation and documentation developed thanks to the new three-dimensional representations of urban space. It is important to note that over and above its theatrical effects, threedimensional modelling is extremely useful to analyse aspects that may also easily be represented in 2D, but which provide better data through graphs, showing the actual conditions. The main characteristic of these models is that they contain a wealth of different kinds of data from different origins. The data sheets that complete the detailed conservation Master Plan, aim at defining a new field of analysis and interpretation of the historical city and would seem to be a valid support to decisions in the different government areas of urban transformations, in terms of recovering and protecting the ancient fabric of Baku.

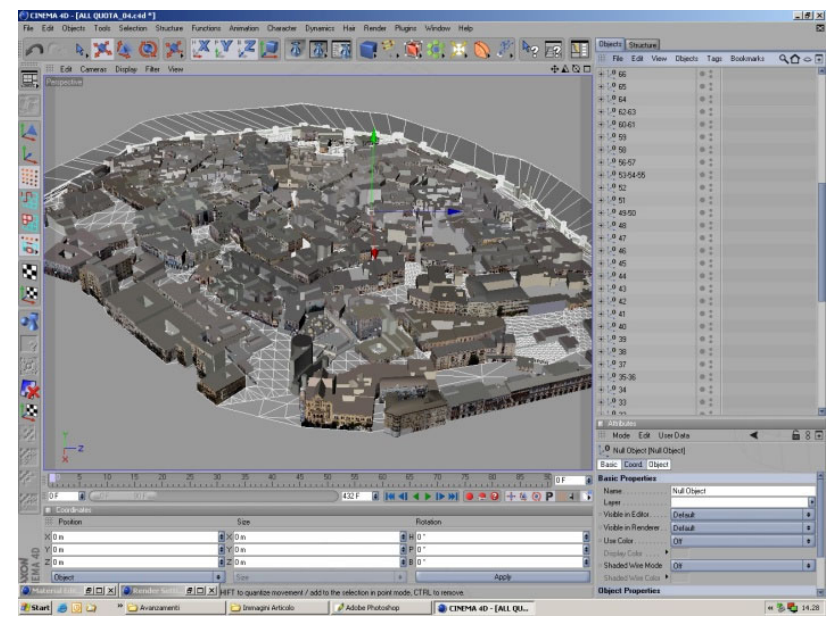

Figure 3: The "global" file presented a hierarchy of 96 blocks altogether, ordered sequentially plus an object making up the town walls.

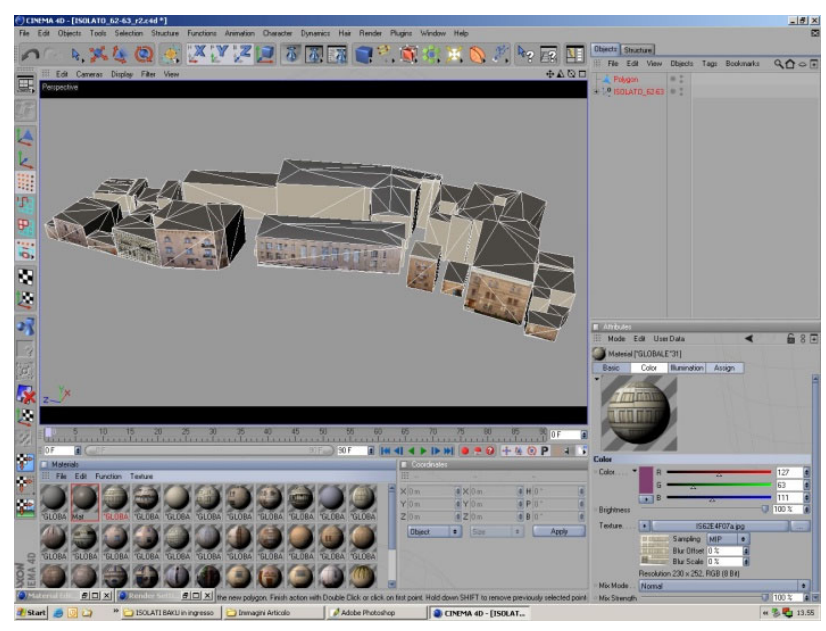

Figure 4: Inside, each block presented the hierarchy described and finishing the model and each could be managed independently from the other.
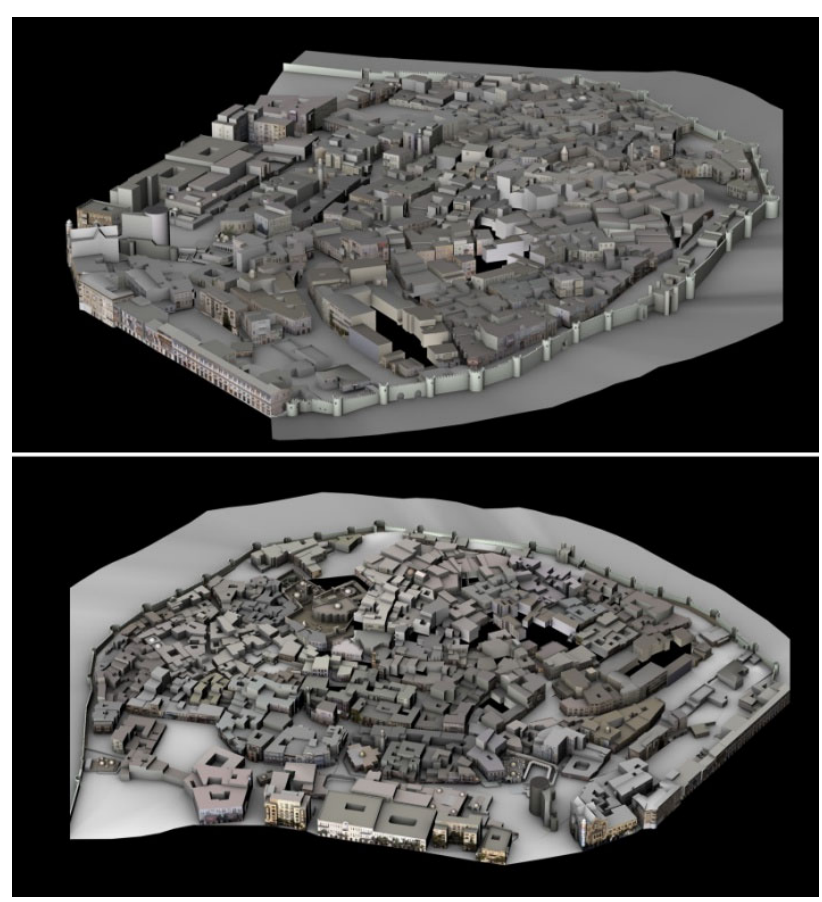

Figure 5: 3D Model of the Historical City

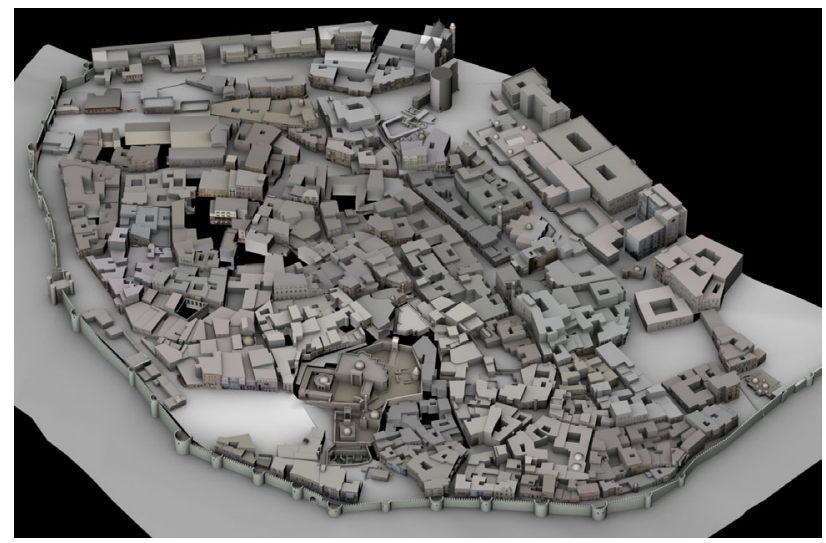

Figure 6: Detail of 3D Model of the Historical City 


\section{References}

Atsuyuki Okabe, Barry Boots, Kokichi Sugihara \& Sung Nok Chiu (2000). Spatial Tessellations - Concepts and Applications of Voronoi Diagrams. 2nd edition. John Wiley, 2000, 671 pages ISBN 0-471-98635-6.

Bertozzi S., Moretti E, Santolini R, 2010. Il bacino del fiume Foglia. Analisi diacronica delle trasformazioni ambientali del paesaggio. Aras Edizioni, pp. 1-109, ISBN: 9788896378205.

Bertozzi S. E Moretti E., 2010. Approccio metodologico per il rilevamento e l'informatizzazione dei geositi. Atti del $4^{\circ}$ Congresso Nazionale di Geologia e Turismo. Sala Polivalente, v.le Aldo Moro 50, Bologna, 21/22 /23 ottobre 2010. Bologna, 21/22/23/10/2010.

Bertozzi S. E Moretti E., 2012. Geographic Information System Instrument for Cultural Heritage Conservation and Valorisation. L. Baratin (Ed) Instruments and Methodologies for Cultural Heritage Conservation and Valorisation. Editor Gabbiano 2012, Ancona, pp. 137-147.

Bertozzi S. E Moretti E., 2011. Approccio metodologico per il rilevamento e l'informatizzazione dei Geositi. In: Atti del Convegno Annuale della Associazione Italiana di Cartografia; 150 Anni di Cartografia in Italia. Accademia Nazionale di Scienze, Lettere e Arti di Modena, Corso Vittorio Emanuele II, 59. Modena 11-12-13 Maggio 2011.

Bertozzi S. E Moretti E., 2011. Metodologia GIS per il rilevamento dei Geositi. Atti $15^{\circ}$ Conferenza Nazionale ASITA, 15 - 18 novembre 2011, Reggia di Colorno.

Gerhard Navratil, Rizwan Bulbul, Andrew U. Frank, 2010. Maintainable $3 D$ Models of Cities, 15th International Conference on Urban Planning and Regional Development in the Information Society, 18 - 20 May 2010, Vienna
M. Corongiu, R. Galetto , M. Rossi, A. Spalla, 2006. Cartografia numerica per $i$ database topografici e il $3 d$ city model dei centri storici, Convegno SIFET, Taranto.

Orlando M.2008. Il ruolo dei sistemi informativi territoriali nel processo di recupero dei centri storici, Franco Angeli, Milano.

Batty M., 2000, "The new urban geography of the third dimension" Environment and Planning B: Planning and Design 27(4) $483-484$

Sibson, R. (1981). A brief description of natural neighbor interpolation (Chapter 2). V. Barnett. Interpreting Multivariate Data. Chichester: John Wiley. pp. 21-36.

Baratin L., Savini C., Morri E., 2009. Indagine sull'evoluzione storica dei pascoli in Sardegna (Sassari) Atti della 12ma Conferenza Italiana Utenti ESRI - GIS In Action - L'importanza dei dati satellitari per le applicazioni GIS, Roma maggio 2009.

Baratin L., Peloso D., 2009. The three-dimensional model as the support for the documentation and planning of Historic Center of Baku (Republic of the Arzebajian). Proceeding International Conference VSMM, Vienna September 2009.

Baratin L., Moretti E., Bertozzi S.,2012. Tyregis: un Gis per il restauro e la valorizzazione del sito archeologico di Tiro in Libano. Atti della 13ma Conferenza Italiana Utenti ESRI Award 2012, Roma aprile 2012 (in press)

\section{Acknowledgements}

Many thanks to SHDARIS State department of the historical and architectural reserve Icheri Sheher in Baku and DEMINE $\mathrm{NGO}$ in Florence for the kind assistance provided during all phases of experimentation. 